\section{The fourth issue of Archaeology International}

$\mathrm{T}$

he main aim of Archaeology International (AI), since its launch in 1997/98, has been to disseminate information about the Institute's diverse research activities worldwide, by publishing short articles that can readily be understood - and I hope enjoyed - by our archaeological and non-archaeological readers alike. We also include each year, as a matter of record, reports from the Director and the coordinators of the primary research groups, a world map of current field projects, and updated lists of academic staff, honorary members, registered research students and PhDs completed during the past year.

This fourth issue maintains the established balance between articles, reports and lists, and it does so without including articles on any of the topics previously featured. Indeed, I am in the happy editorial position of enjoying an embarrassment of riches from which to select the subjects for each year's $A I$, so varied and interesting is the research undertaken by the Institute's large community of staff and students.

The articles in this year's $A I$ reflect, as did those in the previous three issues, "the quality and breadth of [the Institute's] multidisciplinary and thematic approach to the study of the human past" and its aim of ensuring that "the social, political and economic contexts of . . . archaeology are ... appreciated" (see the mission statement on this page). Thus, the articles in this issue demonstrate not only a geographically, chronologically and thematically wide-ranging involvement in the study of the human past, but also the relevance of the research they report to present-day social, economic and political concerns. This is particularly apparent, for example, in the articles in which Elizabeth Graham describes her participation in an initiative to develop local crafts and educational programmes in Belize and Andrew Reid explains how the colonial creation of ethnic stereotypes fuelled the genocide that ravaged Rwanda in 1994.

As a sequel to the retrospective articles that we published last year by two of the Institute's earliest students, Rachel Maxwell-Hyslop and Nancy Sandars, it is a pleasure this year to be able to include further reminiscences of the early post-war years when the Institute occupied St John's Lodge, a spacious and elegant villa in Regent's Park (see Fig. 3 on p. 10). Grace Simpson, who came to the Institute in 1945, recalls those days and in particular how she was influenced by the teaching of Frederick Zeuner, the Institute's (and the world's) first professor of environmental archaeology.

The information summarized in the pages that precede and follow the fourteen articles in this issue show how the Institute is successfully fulfilling its role as a leading international centre of archaeological research. It now has 80 academic staff and over a hundred registered research students (see pp. 60-64); the number of current field projects exceeds 50 (see p. 8); and in the calendar year 2000 more PhDs were awarded than in any previous year. I hope that this issue will succeed in conveying at least some of the vigour and variety of this research activity, and I thank all the contributors who have taken time to write for $A I$ this year and who have submitted without complaint to my sometimes heavy editorial hand.
DOI: http://dx.doi.org/10.5334/ai.0401

\section{Mission statement}

The Institute of Archaeology is a researchled institution recognized also for the excellence of it s teaching. Its mission is:

- Tobeinternationally pre-eminent in the study, and comparative analysis, of world archaeology.

- To enhance its national and international reputation for the quality and breadth of its multidisciplinary and thematic approach to the study of the human past.

- To promote best practice in the management of cultural heritage and in the care and preservation of archaeological artefacts.

- To promote awareness of the problems cau sed by illicit trade in antiquities and the destruction of archaeological heritage that it entails.

- To ensure that the social, political and economic contexts of the practice of archaeology are taught and appreciated.

- To be at the forefront of international research in archaeological sciences.

- To play a major role in furthering the understanding of London's archaeological and historical past.

- To provide archaeological opportunities of the highest quality to all, regardless of background.

\section{Citation of radiocarbon and} calendric dates

The 1997/98 issue of $A I$ included a note (on p. 2) explaining the differences between "conventional" and "calibrated" radiocarbon datesand their relation ship to calendric dates. $A I$ has adopted the recommendation of the Twelfth International Radiocarbon Conference on how dates should be cited, and uses the following typographical conventions:

- calendar years - AD, BC, BP (= before present, defined as before AD 1950)

- conventional radiocarbon years - ad, bc, bp

- calibrated radiocarbon years - cal AD, cal BC, cal BP.

David R. Harris 